\title{
Zum Gedenken an Professor Dr. Mathias Erlei
}

\author{
Justus Haucap 1
}

Online publiziert: 5. August 2019

(C) List-Gesellschaft e.V. 2019

Am 5. April 2019 ist Professor Dr. Mathias Erlei (TU Clausthal) im Alter von nur 55 Jahren völlig überraschend und unerwartet verstorben. Er hinterlässt seine Frau Christina und fünf Kinder. Mathias Erlei war seit 1992 Mitglied der List-Gesellschaft und seit 2015 Mitglied des Editorial Board des List Forums. Von 2013 bis 2017 war er Vorsitzender des wirtschaftspolitischen Ausschusses im Verein für Socialpolitik. In dieser Funktion fungierte er auch als Gasteditor für den jährlichen Tagungsband der Ausschusstagung, der seit 2014 als Sonderheft des List Forums erscheint. Zuletzt hatten Mathias und ich ein umfangreiches Sonderheft zum Thema „Mainstream vs. heterodoxe Ökonomik: Forschungsprogramme im Vergleich“ herausgegeben. Das Erscheinen dieses Sonderbandes hat er leider schon nicht mehr erleben dürfen.

Die ursprüngliche Idee zu diesem Sonderband kam nicht von mir, sondern von Mathias Erlei. Und die Idee reflektiert sein Wirken und seine Einstellung sehr gut, denn zum einen waren seine Interessen - gerade für heutige Volkswirte - sehr, sehr breit und zum anderen war er offen für neue und alternative Theorien und Methoden. Er war ein echter Wissenschaftler, der immer wieder bestehende Orthodoxien hinterfragte. Und er war aus meiner Sicht ein echter Liberaler, der Pluralismus und Vielfalt als einen Wert betrachtete und zugleich vom Segen des Wettbewerbs als Entdeckungs- und auch als Selektionsverfahren überzeugt war. Während manche Volkswirte sich heute durch eine extreme Spezialisierung und teils auch gewisse Engstirnigkeit auszeichnen, war Mathias Erlei das Gegenteil: Er war in vielen Bereichen äußerst belesen und bestens informiert und er war vor allem offen für neue Ideen.

\footnotetext{
J. Haucap $(\bowtie)$

Düsseldorf Institute for Competition Economics (DICE), Heinrich-Heine University of Düsseldorf, Universitätsstr. 1, 40225 Düsseldorf, Deutschland

E-Mail: haucap@dice.hhu.de
} 
Seine wissenschaftliche Laufbahn begann mit dem Studium der Volkswirtschaftslehre in Münster, wo er 1991 auch bei Manfred Borchert mit einer Arbeit über „Unvollkommene Märkte in der keynesianischen Theorie“ mit Summa cum Laude promoviert wurde. Ende des Jahres 1996 erfolgte ebenfalls in Münster die Habilitation mit einer Schrift über ,Institutionen, Märkte und Marktphasen. Allgemeine Transaktionskostentheorie unter spezieller Berücksichtigung der Entwicklungsphasen von Märkten“, welche 1998 bei Mohr Siebeck erschien und die ich selbst in den ifo studien rezensieren durfte. Nach einer Hochschuldozentur in Münster und Vertretungen an den Universitäten Frankfurt und Essen war er dann ab dem Wintersemester 1999/2000 für fast 20 Jahre Inhaber der Professur für Volkswirtschaftslehre am Institut für Wirtschaftswissenschaft der TU Clausthal.

Sein wissenschaftliches Werk umfasst zahlreiche Publikationen. Am bekanntesten ist vermutlich sein mit den Kollegen Martin Leschke und Dirk Sauerland verfasstes Lehrbuch „Neue Institutionenökonomik“, das zahlreichen Studierenden in den letzten 20 Jahren die Denkweise der Neuen Institutionenökonomik nahe gebracht hat. Darüber hinaus hat Mathias Erlei zahlreiche Bücher und Aufsätze verfasst, die einen weiten Bogen spannen. Sein erster Beitrag im List Forum drehte sich vor 25 Jahren um eine Betrachtung der Rauschgiftproblematik aus ökonomischer Sicht - ein Thema, zu dem er im Jahr 1995 als erster Ökonom in Deutschland auch ein Buch herausgab mit dem Titel „Mit dem Markt gegen Drogen!?“ und das ein Plädoyer für eine rationalere, stärker evidenzbasierte Drogenpolitik war. Andere Beiträge von Mathias Erlei behandelten so unterschiedliche Themen wie die institutionenökonomische Theorie der Religion, einen EU-Finanzausgleich, Vertrauensbildung im Internet, diverse organisations- und industrieökonomische Themen und immer wieder verschiedene wirtschaftsethische und methodologische Fragen. Insbesondere die Institutionenökonomik, die evolutorische Ökonomik und die experimentelle Ökonomik prägten sein Denken und gerade auf diesen Gebieten leistete er viele sehr wertvolle Beiträge zum wissenschaftlichen Diskurs und Erkenntnisfortschritt.

Neben seinen wissenschaftlichen Beiträgen war es Mathias Erlei aber auch stets ein Anliegen, die Einsichten der Ökonomik in eine breitere Öffentlichkeit zu transportieren. Seit 2010 war er einer der Autoren des Blogs ,wirtschaftlichefreiheit.de“. In den letzten neun Jahren hat Mathias Erlei hier über 30 Beiträge verfasst, die einen ebenso weiten Bogen spannen wie sein wissenschaftliches Werk. Sein erster Beitrag aus dem Jahr 2010 trug den Titel „Der Segen der bösen und der Fluch der gut gemeinten Tat" und drehte sich um eine wirtschaftsethische Betrachtung von Spekulanten. Sein letzter Beitrag vom 18. Februar dieses Jahres beschäftigte sich mit der Frage, wie hart die EU bei Neuverhandlungen des Brexits verhandeln soll.

Die List-Gesellschaft und das List Forum verdanken Mathias Erlei viel, er war ein inspirierender und sehr geschätzter Kollege. Wir werden ihm ein ehrendes Andenken bewahren. Auch persönlich habe ich Mathias Erlei viel zu verdanken. Er war weit mehr als nur ein Kollege, uns verband ein sehr freundschaftliches Verhältnis. Mathias Erlei war nicht nur externer Gutachter in meinem Habilitationsverfahren an der Universität der Bundeswehr Hamburg, sondern - insbesondere auch im Rahmen des Hohenheimer Oberseminars - ein äußerst konstruktiver Kritiker zahlreicher meiner Manuskripte und der meiner Doktorandinnen und Doktoranden. Seine stets konstruktive Kritik und seine Ideen haben mir oftmals sehr geholfen, meine eigenen 
Gedanken zu präzisieren und Thesen zu hinterfragen. Die List-Gesellschaft und die Herausgeber des List Forums werden Mathias Erlei sehr vermissen. Sein früher Tod hat uns sehr bestürzt. Seiner Frau und seinen Kindern gilt unser tiefes Mitgefühl. 